\title{
SIMULATION BASED RANKING OF VEGETABLE CASH CROPS FOR SUSTAINABLE GREENHOUSE FARMING PRACTICES
}

\author{
Singh, R. K. - MALlicK, J. ${ }^{*}$ HaSAn, M. A. - MOHAMED, M. H. \\ Department of Civil Engineering, College of Engineering, King Khalid University \\ Abha, Kingdom of Saudi Arabia \\ (phone: +96-617-241-8171; fax: +96-617-241-8816) \\ *Corresponding author \\ e-mail: jmallick@kku.edu.sa; phone:+96-617-241-8171; fax:+96-617-241-8816 \\ (Received $23^{\text {rd }}$ Jan 2019; accepted $27^{\text {th }}$ Feb 2019)
}

\begin{abstract}
Choosing vegetable crops in greenhouse farming plays a significant role in the feasibility of sustainable farming practices. The selected crop affects the economic and environmental conditions which in turn influence the sustainability of farming practices. Therefore, a systematic approach is needed to prioritize the most suitable vegetable crop for sustainable farming practices. The current research focuses on prioritizing vegetable crops grown in green house farming in the environment of the Kingdom of Saudi Arabia (KSA), which takes into account comprehensive criteria related to sustainable farming practices. Five major criteria including crop field area, crop field production, cost of production, price of sale and the usage of water have been selected for the five major vegetable crops grown in the green chamber farming of KSA to determine the most sustainable one. The multiple attribute-based decision making (MADM) model has been developed taking into account the KSA Green House Chamber farming system. The research work reported in this study provides useful information for greenhouse farming in Saudi Arabia in particular and also helps policymakers to formulate effective regional policies to improve the gross domestic product and make farmers self-reliant.
\end{abstract}

Keywords: Crop Prioritization; Multiple Attribute Decision Making (MADM); Sustainable Farming Practices; Fuzzy Delphi Method (FDM); Nonlinear Programming (NLP)

\section{Introduction}

In the greenhouse farming system vegetable cash crop prioritization is significant for sustainable farming practices which help the economic development of the nation and promote self-reliance (Nambiar et al, 2001). Due to technological advancement in the farming sector in terms of farm instruments, availability of seeds, manure and irrigation facilities there is considerable increase in farm yields, but as a result of the high rate of population growth the achieved benefit is not sufficient (Pramanik, 2016). There is a misbalance between supply and demand due to the exponential growth of the local and global population. Sustainable greenhouse farming can provide a better solution to bridge the gap between supply and demand (Roy and Chan, 2012). Sustainable greenhouse farming combines the environmental, economic and social factors to achieve the growth and upliftment of humanity, its surrounding life and the environment (Cocklin, 1995).

Greenhouse sustainable farming practices include environmental, economic and social aspects, which are linked to farmers with improved equity, self-sufficiency, reduced risk and good quality of life (Peacock and Sherman, 2010). The economic factors include the crop yield, the system profitability, the economic gain of the farmers, the security of the food for the society. The environmental conditions in semi-arid and arid climatic zones are not favorable for farming because of harsh and extreme temperature. Many agricultural programs were started at different times to ensure food security and rural development (Bailey and Willoughby, 2013). The environmental factors include the nutrient content of 
agricultural soil, the market value of the yield and its quality, the quality of the irrigation water as per the FAO and the carbon credit of the farm and greenhouse gases contribution. The main limiting factor in greenhouse farming is soil and water therefore it is necessary to promote the innovative technologies at the same time spreading the awareness to greenhouse farming community, among the innovative technologies promotion of vegetable cash crops, hydroponics, seawater harvesting also promotion of bio-salinity research and rainwater harvesting.

The selection of a particular set of crop patterns depends on many criteria that can vary from place to place, so that it is difficult to decide on an optimal crop pattern (Qureshi et al., 2018). This may be treated as a system where we have the system input then change within the system and system output the farming vegetable cash crop system requires all the essential parts to produce certain cash crop with relation to surrounding environmental conditions. In the greenhouse farming system largely depends on the tools (Management Policies, Optimum use of Manpower, Mechanizations, Farming Materials, Farming Methods, Economy, Production and Sale).

In the greenhouse farming system management aspects is the important component of the farm if we emphasis this based on system engineering then the components are policies related to farm management, utilization of optimum manpower, the mechanization of the system, the materials of the farming, the farming techniques, the economic aspects of the farm and yield with market value. The second aspect is utilization of sustainable greenhouse farming activities such as economic use of natural resources such as irrigation water, natural soil, wind, sun light and manure, use of natural pesticides (Garg and Dadhich, 2014). The last component is production of cash crops for the benefit of the farmers with focus on environment, economic and social. For achieving the sustainable farming the system input, the system output and things happening within the system should all should be integrated. The employed manpower should be aware with the sustainable farming activities. Mechanized greenhouse farms and equipment viz. plougher, tractors, crusher are used at various stages of the farming activity starting from the preparation of land up to cultivation in the greenhouse the care is also taken to maintain the internal environment for the maximum possible yields it also include the process of plowing, seedling, manure, water and pests applications etc. In Saudi Arabia, water as an important natural resource specially used in sophisticated irrigation system such as drip irrigation and sprinkler systems. Availability of sufficient funds to run the activities and marketing strategies to get the better return are the important aspects of management practices. The prioritization of vegetable cash crops in greenhouse farm can be considered as a strategic decision which may benefit to different stake holders. The climatic factors, economic factors, sustainability, the vegetable crop selection practice in greenhouse are considered to be an important decision which helps the decision makers. Therefore, the crops selection practice is vital for sustainability and better socio-economic conditions.

\section{Review of literature}

The concept of farming sustainability criteria was inducted by Gowda and Jayaramaiah (1998) also extended by Qureshi and Singh (2017) using system approach and management tools. The concept of index was introduced to get the sustainability indicators for the selected criteria and prevailing climatic conditions by Dillon et al. (2009). In order to measure the farm sustainability for the temporal variation (Nambiar et 
al, 2001). The concept of farming sustainability assessment was performed by Zhen et al. (2005). Also a crucial study on the field level management of soil nutrient was carried out by Zhen et al. (2006). The environmental and socio-economic factors were considered and the analysis was carried out by Sydorovych and Wossink $(2008 ; 2009)$ classified sustainability indicators based on the comprehensive data. A study carried out in the Bangladesh related to farming sustainability indicators by Roy and Chan (2012). A study was carried out for the crop selection process using the agricultural landscape by Sorensen et al. (2015).

The different criteria which may be non-dimensional and dimensional in nature can be efficiently handled in the decision making process using the multiple attribute decision models (MADM) this modeling method is used in the prioritizing the alternate solutions even in the case of complicated criteria involved (Rao and Patel, 2010; Venkata Roa, 2008; Geng and Wardlaw, 2013). The diffusion and flow of trace metal in river Ganga a study using MCDM was reported by Srinivas et al. (2017). In the two districts in the Uttar Pradesh state of India viz. Raebareli and Unnao in India, groundwater quality assessment was carried out using GIS and MCDM by Agarwal and Garg (2016) at the same time an spatial vulnerability of flood mapping keeping in view the effect of climate change using MCDM was reported by Song and Chung (2016).

The MADM methods were applied in the various fields of Environmental Engineering and Water Resources Management such as agricultural irrigation water management and water tariff, flood related problems and decision making, at the basin level integrated water resources management, management of city water supply scheme, planning of water quality and quantity at the sustainable level, reduction of water loss due to major and minor reasons in water supply lines, ground water and surface water contamination due to anthropogenic activities and control using modeling techniques by various researchers (Raju et al., 2000; Chitsaz and Banihabib, 2015; Raju and Vasan; Azarnivand et al., 2015; Geng and Wardlaw, 2013; Mutikanga et al., 2011; Carroll et al., 2013; Roozbahani et al., 2012; Behzadian et al., 2010; Latinopoulos, 2008; Srdjevic et al., 2004). The MADM methods are also applied in the area of waste management choices (Karagiannidis and Perkoulidis, 2009), interventions in anaerobic digestion process to manage the feed stock (Rao and Baral, 2011), in the area of manufacturing systems (Rao and Patel, 2010), energy sector such as power plants (Garg et al., 2007) and in the area of robotics for robots selections (Bhangale et al., 2004).

In present study MADM methods are used to prioritize the vegetable cash crops in greenhouse farming system using techniques such as WPM,SAW,TOPSIS and PROMETHEE and the results were compared using optimization package LINGO (LINGO, 2006). The objective of the research as per these backgrounds discussed here are the prioritization of vegetable cash crops in greenhouse farming system taking in account the important criteria for the sustainable farming practices. The development of multi attribute based decision model (MADM) to prioritize the vegetable cash crops in greenhouse farming system. The overall paper is arranged in five parts first part deals with the introduction, the second part deals with the materials and methods, the third part deals with multi attribute based decision models, fourth part deals with the results and discussions and the fifth and last part deals with the conclusions.

In the coming parts the construction of decision matrix is carried out to prioritize the vegetable cash crops grown in the Greenhouse for sustainable farming practices and maximum returns for five most preferred vegetable crops viz. (Cucurbitaceae, Solanum lycopersicum, Capsicum annuum, Solanum melongena, Abelmoschus esculentus) with 
respect to different dimensional and no dimensional criteria (crop field area, crop field production, cost of production, price of sale, usage of water) based on the importance of the objective under study. The constraints of minimum available farming area has been fixed as per the percentage of system of pattern of cropping (Cucurbitaceae 35\%, Solanum lycopersicum 36\%, Capsicum annuum 10\%, Solanum melongena 11\%, Abelmoschus esculentus $7 \%$ ) of farming area in Greenhouse system. In order to control the dominance of most profitable crop the farm area constraints for certain crops are fixed as minimum in the total farming area. The type of the soil in the farming area varies farm are sandy clay loam, clay loam and clay. The water production function (WFP) is referred as the ratio of crop production and water use that is the influencing factor of the model. The price of the crop product is decided based on the guideline of the Ministry of Agriculture Saudi Arabia.

The constraints such as farming area, crop yield, cost of crop production per unit area, price of crop product per unit mass. The cost of farming was qualitative (value based) and irrigation water use is quantitative. Depending on the expert opinion of farming area the inter relationships between the attributes has been established. The beneficial attributes are the farm area and farm yield whereas the non-beneficial attributes are the price of sale and cost of production. In the present study the qualitative attributes were considered and put under the ranked value judgement with a fuzzy conversion scale. The crisp score were obtained using the fuzzy set theory (Chen and Hwang, 1992). The decision matrix shown in Table 1 is formed based on the data collected through different departments, experts' opinion.

Table 1. Model Attribute Simulation of Green House Vegetable Cash Crops used

\begin{tabular}{c|c|c|c|c|c}
\hline S. No. & $\begin{array}{c}\text { Cash Crops used } \\
\text { (Alternatives) }\end{array}$ & $\begin{array}{c}\text { Crop Field } \\
\text { Area } \\
(\mathbf{C F A})\left(\mathbf{m}^{2}\right) \\
\mathbf{0 0 0}\end{array}$ & $\begin{array}{c}\text { Crop Field } \\
\text { Production } \\
(\mathbf{C R F}) \\
\left(\mathbf{K g} / \mathbf{m}^{2}\right)\end{array}$ & $\begin{array}{c}\text { Cost of } \\
\text { Production } \\
(\mathbf{C P}) \\
\left(\mathbf{U S D} / \mathbf{m}^{2}\right)\end{array}$ & $\begin{array}{c}\text { Price of } \\
\text { sale (PS) } \\
\text { USD per } \\
\mathbf{K g}\end{array}$ \\
\hline 1. & Cucurbitaceae (A1)* & 109800 & 15.4000 & 4.04 & 1.07 \\
2. & Solanum lycopersicum (A2)* & 110000 & 16.8000 & 4.68 & 1.07 \\
4. & Capsicum annuum (A3)* & 35000 & 13.4000 & 4.80 & 1.07 \\
5. & Solanum melongena (A4)* & 34000 & 9.7000 & 4.40 & 0.80 \\
\hline
\end{tabular}

* Cucurbitaceae $(\mathrm{A} 1)=$ Cucumber; Solanum lycopersicum $(\mathrm{A} 2)$ = Tomato; Capsicum annuum $(\mathrm{A} 3)=$ Green pepper; Solanum melongena (A4) = Eggplant; Abelmoschus esculentus $(\mathrm{A} 5)=$ Okra

\section{Materials and methods}

\section{Study area}

In the Kingdom of Saudi Arabia greenhouse farming is promising venture. Recognizing its yields per unit area of the farm and the effective use of scare natural resource viz. water and soil. Saudi Arabia is putting the sincere efforts to enhance the greenhouse farming activities. The trend in increase in the greenhouse farm in past twenty 
years double in the numbers and more than eighteen times in yields. The number and production in greenhouse farms has increased from 104 and 26 tons in the year 1984 to 295 and 142 tons in 1999. In the Saudi Arabia Greenhouse chambers mostly produce vegetables which is around $42 \%$ of the total production the Cucurbitaceae and Solanum lycopersicum are the most produced vegetable crops producing more than $85 \%$ of the total production (Ministry of Agriculture and Water, 2001).There are many factors which affects the prioritization of crop type in Greenhouse farming. The criteria like available irrigation water in terms of quality and quantity, nutrient value of soil, financial conditions, climatic conditions, skill level of workers etc. play important role in agricultural farming.

In this paper the effort is made for the sustainable greenhouse farming for efficient greenhouse farming expansion is the need of the hour and this should be exploited and utilized in precise and most efficient way in Saudi Arabia. The figure below shows the green chamber farms located at $18^{\circ} 06^{\prime} 25.2^{\prime \prime} \mathrm{N}, 42^{\circ} 53^{\prime} 45.3^{\prime \prime} \mathrm{E}$ (DMS WGS 84) in the Asir region (Fig. 1).

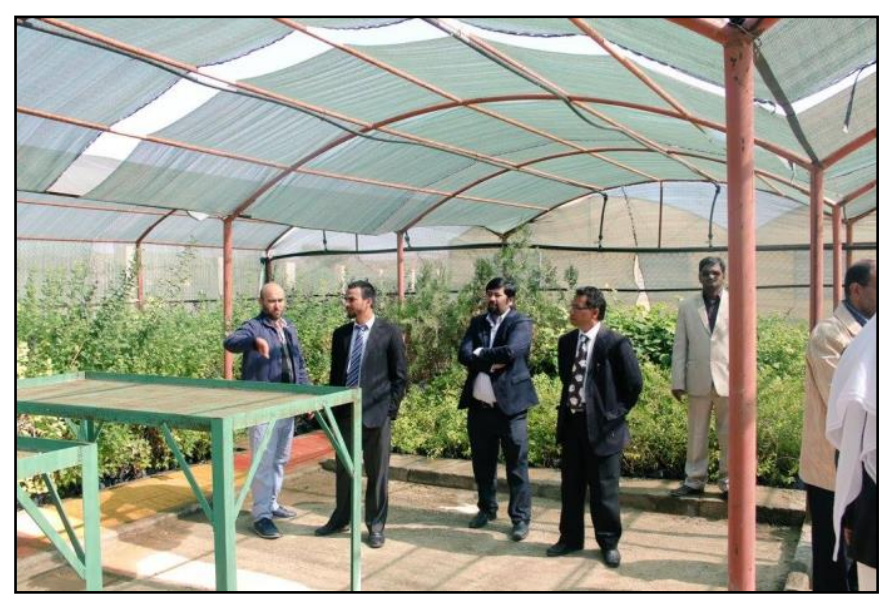

Figure 1. Green Chamber Farms in Aseer Region in the Kingdom of Saudi Arabia

\section{The MADM methods}

\section{Weighted Product Method (WPM) method}

In this method all possible alternative is compared with the other alternative by taking the product of number of ratios, one for every selected criterion. The relative weight of the concern criterion is taken as the power to the ratio, (Chen and Hwang, 1992) as mentioned below (Eq.1):

$$
P_{i}=\prod_{j=1}^{M}\left[\left(m_{i j}\right)_{n o r m a l}\right] w_{j}
$$

The $\left(\mathrm{m}_{\mathrm{ij}}\right)$ normal is normalized value of an alternative with respect to an attribute is raised to the with the relative weight of the concern attribute. The best alternative is selected with the value with highest $P_{i}$. 


\section{Simple Additive Weighting Method (SAW) method}

This method was first developed by (Edwards et al., 1982). The mathematical form of this method (Eq. 2) can be written as follows:

$$
P_{i}=\prod_{j=1}^{M}\left[\left(m_{i j}\right)_{n o r m a l}\right] w_{j}
$$

The different terms in the above equation can be defined as, $\mathrm{P}_{\mathrm{i}}$ is overall score of the crop alternative $\left(A_{i}\right), W_{j}$ is the weight of importance of $j$ th criterion, $m_{i j}$ is the measure of the performance of the jth performance criterion and the $\left(\mathrm{m}_{\mathrm{ij}}\right)$ normal represents the normalized value of $\mathrm{m}_{\mathrm{ij}}$. This method can be also used for non-identical units of measure when the values of decision matrix is normalized.

The Technique for Order of Preference by Similarity to Ideal Solution method (TOPSIS)

The TOPSIS process is carried out in six steps as follows:

Step 1. Creation of evaluation matrix:

Create an evaluation matrix consisting of $\mathrm{m}$ alternatives and $\mathrm{n}$ criteria, with the intersection of each alternative and criteria given as $x_{i j}$ we therefore have a matrix $\left(x_{i j}\right)_{m x n}$. This matrix is considered as a decision matrix with the dimensions mxn. This matrix formation takes care of the dimensional and non-dimensional units.

Step 2. Creation of relative importance matrix:

The relative importance of one attribute is compared with the other attribute. This also helps in calculating the weight of each criteria (Saaty, 1980).

Step 3. Development of normalized decision matrix (Eq.3):

The matrix $\left(x_{i j}\right)_{m x n}$ is then normalized to form the matrix

$$
R=\left(r_{i j}\right)_{m x n}
$$

using the normalization method (Eq.4):

$$
r_{i j}=\frac{x_{i j}}{\sqrt{\sum_{i=1}^{m} x_{i j}^{2}}},=1,2, \ldots, m, j=1,2, \ldots, n
$$

Step 4. Development of weighted normalized matrix:

Calculate the weighted normalized decision matrix (Eqs.5):

$$
\begin{gathered}
T=\left(t_{i j}\right)_{m x n}=\left(w_{j} r_{i j}\right)_{m x n^{\prime}} i=1,2, \ldots, m \\
w_{j}=W_{j} / \sum_{j=1}^{n} W_{j}, j=1,2, \ldots, n
\end{gathered}
$$

Where 
$\sum_{j=1}^{n} w_{j}=1$

So that, and $W_{j}$ is the original weight given to the indicator $v_{j}, j=1,2, \ldots, n$.

Step 5. Determination of best and worst conditions (Eq.6):

$$
A_{w}=\left\{\left\langle\max \left(t_{i j}|i=1,2, \ldots, m|\right) j \in J_{-}\right\rangle,\left\langle\min \left(t_{i j}|i=1,2, \ldots, m|\right) j \in J_{+}\right\rangle\right\} \equiv\left\{t_{w j}|j=1,2, \ldots, n|\right\} \quad \text { (Eq.6) }
$$

Determine the worst alternative $\left(A_{w}\right)$ and the best alternative $\left(A_{b}\right)(E q .7)$ :

$$
A_{b}=\left\{\left\langle\min \left(t_{i j}|i=1,2, \ldots, m|\right) j \in J_{-}\right\rangle,\left\langle\max \left(t_{i j}|i=1,2, \ldots, m|\right) j \in J_{+}\right\rangle\right\} \equiv\left\{t_{w j}|j=1,2, \ldots, n|\right\}(E q .7)
$$

Where,

$J_{+}=\{j=1,2, \ldots, n|j|\}$

associated with the criteria having a positive impact, and

$J_{-}=\{j=1,2, \ldots, n|j|\}$ associated with the criteria having a negative impact.

Calculate the distance between the target alternative $i$ and the worst condition $A_{w}$ as below mentioned (Eq.8):

$$
d_{i w}=\sqrt{\sum_{j=1}^{n}\left(t_{i j}-t_{w j}\right)^{2}}, i=1,2, \ldots, m
$$

and the distance between the alternative $i$ and the best condition $A_{b}$ (Eq.9):

$$
d_{i b}=\sqrt{\sum_{j=1}^{n}\left(t_{i j}-t_{b j}\right)^{2}}, i=1,2, \ldots, m
$$

Where $d_{i w}$ and $d_{i b}$ are L2-norm distances from the target alternative $i$ to the worst and best conditions, respectively.

Step 6. Euclidean distance:

Calculate the similarity to the worst condition as mentioned below (Eq.10):

$$
S_{i w}=d_{i w} /\left(d_{i w}+d_{i b}\right), 0 \leq S_{i w} \leq 1, i=1,2, \ldots, m
$$

$S_{i w}=1$ if and only if the alternative solution has the best condition; and

$S_{i w}=0$ if and only if the alternative solution has the worst condition.

Step 7. Prioritization of alternatives:

Rank the alternatives according to $S_{i w}(i=1,2, \ldots, m)$

\section{Fuzzy Delphi Method (FDM)}

The general Delphi method and the fuzzy set theory was clubbed together for the first time by (Ishikawa et al., 1993) and developed the method known as Fuzzy Delphi Method (FDM). In order to solve the fuzziness of general understanding of professional ideas (Noorderhaben, 1995) used the FDM. The fuzziness of the general opinion of the professional could be solved using FDM, and can be evaluated on a more flexible scale. 
The questionnaires can be improved for its quality and efficiency thus more parameters could be screened through the fuzzy set theory. The fuzzy numbers used for this purpose is shown in Table 2 and the fuzzy scale is shown in Figure 2.

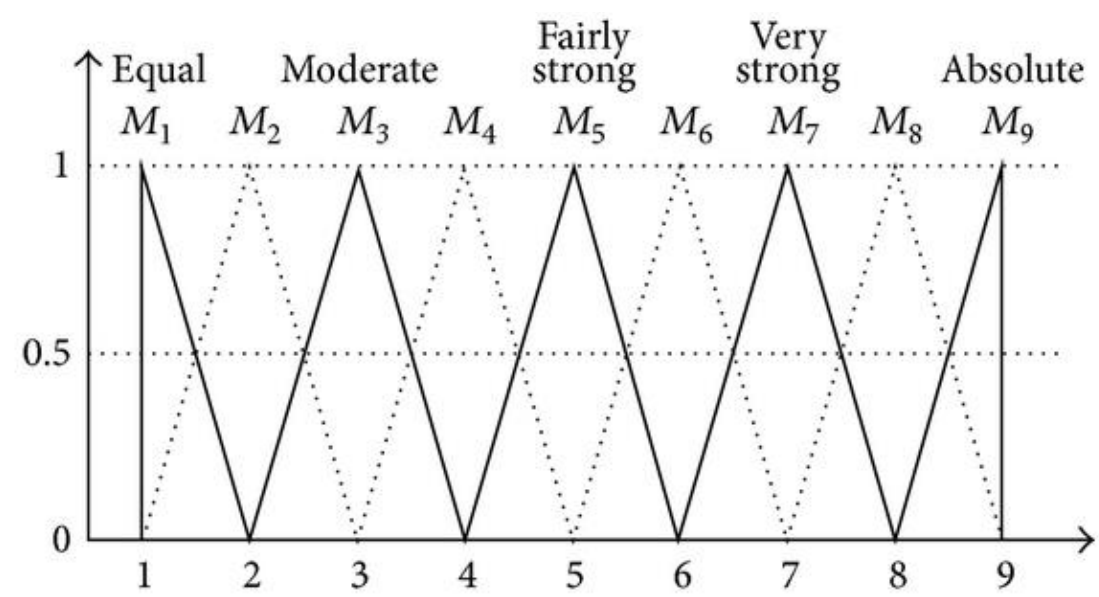

Figure 2. The fuzzy number scale (Li et al., 2013)

Table 2. Fuzzy numbers and definition

\begin{tabular}{c|c}
\hline Fuzzy numbers & Definition \\
\hline $1(1,1,1)$ & Equally important \\
$2(1,2,3)$ & Equally to moderate important \\
$3(2,3,4)$ & Moderately more important \\
$4(3,4,5)$ & Moderately and strongly important \\
$5(4,5,6)$ & More strongly important \\
$6(5,6,7)$ & Strongly and very strongly important \\
$7(6,7,8)$ & More very strongly important \\
$8(7,8,9)$ & Very strongly to extremely important \\
$9(8,9,9)$ & Extremely more important \\
\hline
\end{tabular}

The steps involved in Fuzzy Delphi Method (FDM) are as follows:

a. The decision group opinion data base generation:

The linguistic variables in the questionnaire is used to generate the score of factors important in the study as per the expert opinion.

b. The triangular fuzzy numbers set up:

As per the experts opinion triangular fuzzy number generated are used to get the evaluated values and their significance triangular fuzzy number for the alternate factors are generated. In this study the geometric mean model proposed by (Klir and Yuan, 1995) is used for FDM to get the general understanding of group decision. The formula used is given as follows. Assuming $\mathrm{n}$ number of professional whose element is given by number $i$ and the significance of number $j$ then the fuzzy weight.

$$
\widetilde{w_{l j}}=\left(a_{i j} ; b_{i j} ; c_{i j}\right), i=1,2 ; \ldots \ldots \ldots ; n ; j=1,2 ; \ldots \ldots \ldots ; m \text { then the } \widetilde{w_{J}} \text { fuzzy }
$$

weighting of no. $\mathrm{j}$ element is presented as $\widetilde{w} j=\left(a_{j}, b_{j} ; c_{j}\right) ; j=1,2 ; \ldots \ldots, m$. 
Among which $a=\operatorname{Max}_{i} a_{i j}, b_{j}=\frac{1}{n \sum_{n-1}^{n} b i j}, c=\operatorname{Max}_{i} C_{i j}$

c. Defuzzification

The absolute value $S_{\mathrm{j}}$ is obtained by using the ordinary center of gravity method the process is called defuzzification and the parameter used is fuzzy weight $\mathrm{w}_{\mathrm{j}}$ is calculated as follows in Equation 11.

$$
S_{j}=\frac{\left(a_{j}+b_{j}+c_{j}\right)}{3} \text { where } j=1,2,3, \ldots \ldots \ldots, m
$$

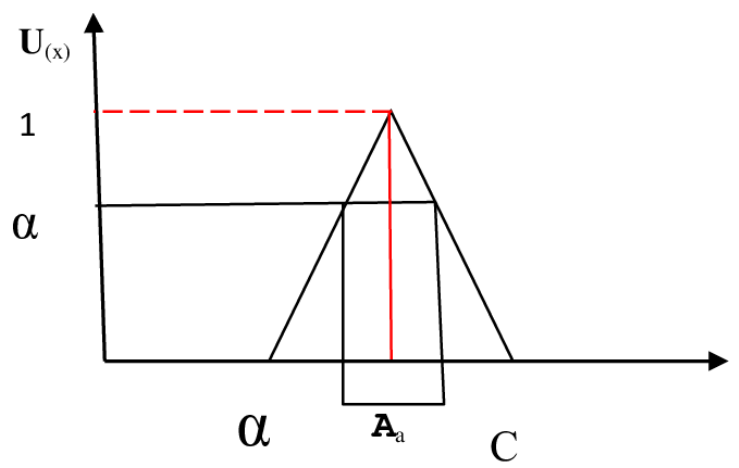

Figure 3. Fuzzy Delphi method diagram (Moradi et al. 2014)

If $S_{j} \geq \alpha$, then the no. $\mathrm{j}$ factor is the evaluation index

If $S_{j}<\alpha$ then delete no. $\mathrm{j}$ factor

The solution obtained using FDM is reported in Table 6 and the important criteria with their definition is mentioned in Table 3.

Table 3. Important criteria and definition

\begin{tabular}{|c|c|c|}
\hline Criteria & Abbreviation & Definition \\
\hline $\begin{array}{l}\text { Crop Field } \\
\text { Area }\end{array}$ & CFA & $\begin{array}{c}\text { The study taken here is the Greenhouse chamber so the land area } \\
\text { located, under this category around } 42 \% \text { of the land out of total } \\
\text { vegetable crops grown in KSA is put. }\end{array}$ \\
\hline $\begin{array}{l}\text { Crop Field } \\
\text { Production }\end{array}$ & $\mathrm{CRF}$ & $\begin{array}{l}\text { This is the yield of crops in ton per unit area of the land in ha for } \\
\text { example in the case of Cucurbitaceae } 154 \text { ton/ha. }\end{array}$ \\
\hline $\begin{array}{l}\text { Cost of } \\
\text { Production }\end{array}$ & $\mathrm{CP}$ & $\begin{array}{l}\text { This include all type of the expenditures involved per unit production } \\
\text { of the crop for example in the case of Abelmoschus esculentus it is } \\
\text { SR } 21562 / \text { ha. }\end{array}$ \\
\hline Price of sale & PS & $\begin{array}{l}\text { This the rate received in the market per unit produce of the crop on } \\
\text { average in the case of Cucurbitaceae it is around } \mathrm{SR} 4 / \mathrm{Kg} \text {. }\end{array}$ \\
\hline $\begin{array}{l}\text { Usage of } \\
\text { water }\end{array}$ & US & $\begin{array}{l}\text { This is amount of water required per unit area of the land per } \\
\text { cropping period it is quantitative value (ha-m) but if we compare } \\
\text { crops with each other it can be taken as qualitative. }\end{array}$ \\
\hline
\end{tabular}

\section{The Nonlinear Programming (NLP) model and solution}

In the NLP model the objective function is to maximize the profit and the constraints were set up on the availability of water quantity using the Lingo (Shrivastava et al., 2012). The defined objective function of the problem is as follows (Eq.12). 


$$
\text { Maximise } F=(P Y-C) A
$$

In the above equation the function $\mathrm{F}$ stands for the net profit, SR (Kingdom of Saudi Arabia, Currency); $\mathrm{P}$ is the market value of vegetable in $\mathrm{SR} / \mathrm{kg}$; $\mathrm{C}$ is the cost of cultivation in SR/ha; Y is the yield of vegetable per unit area of the land in $\mathrm{Kg} / \mathrm{ha}$; A is the total area of cultivation in ha. The model took in account the various constraints. The water availability for the groundwater source is considered as a constraint. The total area is divided in sub area on the basis soil and land availability constraint. The agricultural land area to some crops is fixed as minimum so that the crop with high market value should not dominant over the complete agricultural area. The cultivated area and irrigation water depth is considered as positive decision variable.

\section{Results and discussion}

In TOPSIS model the formulation matrix developed as shown in Table 1 is utilized in this section to develop the normalized matrix as written by Equation 13 in order to remove the dimensions the entry in the matrix from 0 to 1.

$$
\left[\begin{array}{cccccc}
\downarrow \rightarrow & C F A & C F P & C P & P S & U W \\
A 1 & 0.998 & 0.917 & 0.790 & 0.750 & 0.817 \\
A 2 & 1.00 & 1.00 & 0.683 & 0.750 & 0.670 \\
A 3 & 0.318 & 0.798 & 0.666 & 0.750 & 0.568 \\
A 4 & 0.309 & 0.577 & 0.728 & 1.00 & 0.761 \\
A 5 & 0.191 & 0.095 & 1.00 & 0.375 & 1.00
\end{array}\right]
$$

From the decision matrix in Equation 13, the normalized matrix is developed as shown in Equation 14.

$$
\left[\begin{array}{lllll}
0.670 & 0.546 & 0.451 & 0.446 & 0.470 \\
0.671 & 0.596 & 0.390 & 0.446 & 0.386 \\
0.213 & 0.475 & 0.381 & 0.446 & 0.327 \\
0.207 & 0.344 & 0.416 & 0.595 & 0.438 \\
0.128 & 0.057 & 0.571 & 0.223 & 0.576
\end{array}\right]
$$

The relative importance matrix developed is shown in Equation 15 this is based on analytic hierarchy process first developed by (Saaty, 1980), then the weight of all the criteria is computed as shown in Equation 16. The consistency ratio (CR) is 0.08 which is less than 0.1 hence it depicts good consistency with the decision.

$$
\left[\begin{array}{cccccc}
\downarrow \rightarrow & C F A & C F P & C P & P S & U W \\
C F A & 1 & 4 & 3 & 2 & 5 \\
C F P & 1 / 4 & 1 & 1 / 3 & 1 / 2 & 2 \\
C P & 1 / 3 & 3 & 1 & 4 & 1 / 3 \\
P S & 1 / 2 & 2 & 1 / 2 & 1 & 1 / 2 \\
U W & 1 / 5 & 1 / 2 & 1 / 3 & 2 & 1
\end{array}\right]
$$

As per the method proposed by (Saaty, 1980) the weight for all the criteria is calculated and reported in the following Equation 16.

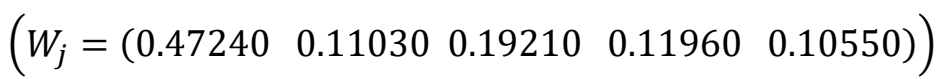


In Equation 17 the weighted normalized matrix is written which is obtained by multiplying weights into normalized matrix.

$$
\left[\begin{array}{lllll}
0.316 & 0.060 & 0.087 & 0.053 & 0.049 \\
0.316 & 0.066 & 0.075 & 0.053 & 0.041 \\
0.101 & 0.052 & 0.073 & 0.053 & 0.034 \\
0.098 & 0.038 & 0.079 & 0.071 & 0.046 \\
0.060 & 0.006 & 0.109 & 0.027 & 0.061
\end{array}\right]
$$

In the next step the positive-ideal (best) and the negative-ideal (worst) is calculated (Eq. 18) as depicted in the Table 4 subsequently the positive and the negative separation measure were calculated as shown in Table 5 the relative closeness value is calculated for all the options and is shown in Table 3.

$\left[\begin{array}{lllll}A 11 & A 12 & A 13 & A 14 & A 15 \\ B 11 & B 12 & B 13 & B 14 & B 15 \\ C 11 & C 12 & C 13 & C 14 & C 15 \\ D 11 & D 12 & D 13 & D 14 & D 15 \\ E 11 & E 12 & E 13 & E 14 & E 15\end{array}\right]$

Table 4. For different attributes best (+ve) and worst (-ve) Results

\begin{tabular}{c|l|l}
\hline S. No. & \multicolumn{1}{|c}{ Ideal Best } & \multicolumn{1}{c}{ Ideal Worst } \\
\hline 1. & $I_{C F A}^{+}=0.316$ & $I_{C F A}^{-}=0.060$ \\
2. & $I_{C F P}^{+}=0.066$ & $I_{C F P}^{-}=0.006$ \\
3. & $I_{C P}^{+}=0.109$ & $I_{C P}^{-}=0.073$ \\
4. & $I_{P S}^{+}=0.071$ & $I_{P S}^{-}=0.027$ \\
5. & $I_{U W}^{+}=0.061$ & $I_{U W}^{-}=0.061$ \\
\hline
\end{tabular}

Table 5. For the positive ideal and negative ideal solution separation measure

\begin{tabular}{|c|c|c|c|}
\hline S. No. & Positive Separation Measure & Negative Separation Measure & Relative Closeness \\
\hline 1. & $P_{\text {Cucurbitaceae }}^{+}=0.031$ & $P_{\text {Cucurbitaceae }}^{-}=0.264$ & $\begin{array}{l}P_{\text {Cucurbitaceae }} \\
=0.895\end{array}$ \\
\hline 2. & $P_{\text {Solanumlycopersicum }}^{+}=0.043$ & $P_{\text {Solanumlycopersicum }}^{-}=0.264$ & $\begin{array}{l}P_{\text {Solanumlycopersicum }} \\
=0.859\end{array}$ \\
\hline 3. & $P_{\text {Capsicum annuum }}^{+}=0.221$ & $P_{\text {Capsicum annuum }}^{-}=0.067$ & $\begin{array}{l}P_{\text {Capsicum annuum }} \\
=0.233\end{array}$ \\
\hline 4. & $P_{\text {Solanum melongena }}^{+}=0.222$ & $P_{\text {Solanum melongena }}^{-}=0.068$ & $\begin{array}{l}P_{\text {Solanum melongena }} \\
=0.235\end{array}$ \\
\hline 5. & $P_{\text {Abelmoschus esculentus }}^{+}=0.267$ & $P_{\text {Abelmoschus esculentus }}^{-}=0.554$ & $\begin{array}{l}P_{\text {Abelmoschus esculentus }} \\
=0.554\end{array}$ \\
\hline
\end{tabular}

Table 5 shows the calculation details of relative closness for the crops , $P_{\text {Cucurbitaceae, }}$

$P_{\text {Solanumly copersicum, }} P_{\text {Capsicum annuum, }}, P_{\text {Solanum melongena }}$ and $P_{\text {Abelmoschus esculentus. The Fuzzy }}$ Delphi Method (FDM) model formulation is discussed as above. The detail calculations and results obtained are in Table 6. 
Table 6. The Result of the FDM

\begin{tabular}{|c|c|c|c|c|c|c|c|c|c|c|}
\hline $\begin{array}{l}\text { Preference } \\
\text { values }\end{array}$ & D1 & D2 & D3 & $\alpha$ & $\boldsymbol{\beta}$ & $\gamma$ & $\mathbf{U}$ & $\mathbf{M}$ & $\mathbf{L}$ & $\begin{array}{c}\text { Best non fuzzy } \\
\text { performance } \\
\text { [(U-L)+(M- } \\
\text { L) }] / 3+L\end{array}$ \\
\hline Cucurbitaceae & $(8,9,9)$ & $(8,9,9)$ & $(7,8,9)$ & 7.7 & 8.7 & 9.0 & 9.0 & 8.6 & 7.6 & 8.445 \\
\hline $\begin{array}{c}\text { Solanum } \\
\text { lycopersicum }\end{array}$ & $(7,8,9)$ & $(8,9,9)$ & $(7,8,9)$ & 7.7 & 8.3 & 9.0 & 9.0 & 8.3 & 7.3 & 8.222 \\
\hline $\begin{array}{c}\text { Abelmoschus } \\
\text { esculentus }\end{array}$ & $(7,8,9)$ & $(8,9,9)$ & $(6,7,8)$ & 7.0 & 8.0 & 8.7 & 8.6 & 8.0 & 7.0 & 7.889 \\
\hline $\begin{array}{l}\text { Solanum } \\
\text { melongena }\end{array}$ & $(7,8,9)$ & $(6,7,8)$ & $(8,9,9)$ & 7.0 & 7.7 & 8.7 & 8.6 & 7.7 & 7.0 & 7.000 \\
\hline $\begin{array}{l}\text { Capsicum } \\
\text { апnиит }\end{array}$ & $(6,7,8)$ & $(6,7,8)$ & $(6,7,8)$ & 6.0 & 7.0 & 8.0 & 8.0 & 7.0 & 6.0 & 7.777 \\
\hline
\end{tabular}

The MADM techniques are used here to prioritize the vegetable cash crops grown in Greenhouse chamber in local climatic and socio-economic conditions which prevails the different criteria for the different attributes in the Kingdom of Saudi Arabia. The MADM techniques adopted here are the (WPM, SAW, TOPSIS and FDM). In order to analyze the alternatives, four methods (SAW, WPM, TOPSIS and FDM) of MADM approach is used in the present study. The selection index values computed by all the techniques are shown in Table 7 the crop prioritization is carried out by the highest index value for first and the lowest index value for the last crop. This is observed that some variations are there when we apply the different techniques due to its different mathematical formulation for the similar parameters. The WPM and SAW methods give the Cucurbitaceae is on top priority followed by Solanum lycopersicum same trend was found by TOPSIS and FDM. The variation is found in the case of Abelmoschus esculentus and Solanum melongena may be due to inclusion of logical interrelationship among the criteria's are taken in account by estimating the separation measure to the pairwise comparison and ideal solution. The Table 6 depict the result of MADM approach used. In comparison with the NLP model results TOSIS and FDM performance was satisfactory. In NLP model and all other MADM techniques the Cucurbitaceae followed by Solanum lycopersicum is most preferred crop, the NLP is solved using LINGO model. For most sustainable Greenhouse practices the importance should be given to land availability, social-economic and environmental factors.

Table 7. Tabulated values of index using WPM, SAW, TOPSIS and FDM method

\begin{tabular}{c|c|c|c|c}
\hline Index values & WPM & SAW & TOPSIS & FDM \\
\hline PCucurbitaceae & 0.894 & 0.900 & 0.895 & 8.445 \\
PSolanum lycopersicum & 0.861 & 0.874 & 0.859 & 8.222 \\
PCapsicum annuum & 0.569 & 0.516 & 0.233 & 7.777 \\
PSolanum melongena & 0.494 & 0.549 & 0.235 & 7.000 \\
PAbelmoschus esculentus & 0.314 & 0.443 & 0.554 & 7.889 \\
\hline
\end{tabular}

\section{Ranking of alternative crops}

WPM Cucurbitaceae-Solanum lycopersicum-Capsicum annuum-Solanum melongena-Abelmoschus esculentus, SAW Cucurbitaceae-Solanum lycopersicum - 
Solanum melongena- Capsicum annuum-Abelmoschus esculentus, TOPSIS Cucurbitaceae-Solanum lycopersicum-Abelmoschus esculentus-Capsicum annuumSolanum melongena, FDM Cucurbitaceae-Solanum lycopersicum-Abelmoschus esculentus-Capsicum annuum-Solanum melongena.

\section{Conclusions}

In this research work the prioritization of most commonly grown vegetable cash crop is made based on the MADM modeling in The Kingdom Saudi Arabia for the sustainable agricultural practices and local climatic and socio-economic conditions this will help the policy maker and Greenhouse farmers in sustainable agricultural practices. The results obtained were analyzed and compared with LINGO model results. The different major criteria selected in the prioritization are the farming area, irrigation water required per unit area, market value of crop yield per unit mass, cost of farming per unit area were decided for each vegetable cash crop grown in the Greenhouse from the collected data source. The methodologies used in simulation modeling are WPM, SAW, TOPSIS and FDM were employed for ranking to each selected crops. The results calculated by WPM and the SAW were little different may be because of weightages chosen to each criteria may not be in comparison of it. The output from the TOPSIS and FDM helped strongly in prioritization of the vegetable cash crops. These two methods permit the policy maker and farmers (decision makers) inclusion or removal of any attribute based on the importance of the criteria with respect to goal of the study. The best possible close hypothetical solution is obtained measuring separation measure, ideal best and ideal worst using TOPSIS method. The prioritization of vegetable cash crops was carried out by FDM method. The results were compared with LINGO model results and found to be satisfactory. Since the computation time required in NLP is more so the quick decision can be taken by MADM. The recommendations for future work are that the system-based process need to be adopted by incorporating multi-criteria methods and using these methods more in the process of crop selection, the other aspect takes into account the more sustainability-based criteria and ecological aspects in order to improve decision making process.

Acknowledgements. Authors thankfully acknowledged the Deanship of Scientific Research for proving administrative and financial supports. Funding for this work has been provided by the Deanship of Scientific Research; King Khalid University, Ministry of Education, Kingdom of Saudi Arabia under award numbers R.G.P.1/28/38.

Conflict of Interests. The authors declare no conflict of interests.

\section{REFERENCES}

[1] Agarwal, R., Garg, P. K. (2016): Remote sensing and GIS based groundwater potential \& recharge zones mapping using multi-criteria decision making technique. - Water Resoue Manage 30(1): 243-260.

[2] Bailey, R., Willoughby, R. (2013). Edible Oil: Food Security in the Gulf. - Chatham House, London: 10-2.

[3] Behzadian, M., Kazemzadeh, R. B., Albadvi, A., Aghdasi, M. (2010): PROMETHEE: a comprehensive literature review on methodologies and applications. - Eur. J. Oper. Res. 200(1): 198-215. 
[4] Bhangale, P. P., Agrawal, V. P., Saha, S. K. (2004): Attribute based specification, comparison and selection of a robot. - Mech. Mach. Theory 39(12): 1345-1366.

[5] Carroll, S., Liu, A., Dawes, L., Hargreaves, M., Goonetilleke, A. (2013): Role of land use and seasonal factors in water quality degradations. - Water Resoue Manage 27(9): 34333440 .

[6] Chen, S. J., Hwang, C. L. (1992): Fuzzy multiple attribute decision making methods. In: Fuzzy Multiple Attribute Decision Making. - Springer Berlin Heidelberg: 289- 486.

[7] Chitsaz, N., Banihabib, M. E. (2015): Comparison of different multi criteria decisionmaking models in prioritizing flood management alternatives. - Water Resoue Manage 29(8): 2503-2525.

[8] Cocklin, C. R. (1995). Agriculture, society and environment: discourses on sustainability. - International Journal of Sustainable Development and World Ecology 2: 240-56

[9] Dillon, E. J., Hennessy, T, Hynes, S. (2009): Towards measurement of farm sustainabilityan Irish case study. - Contributed paper prepared for presentation at the international association of 108 Environmentalist (2012) 32: 99-110 Agricultural Economists Conference, Beijing, China: 16-22.

[10] Edwards, W., Newman, J. R., Snapper, K., Seaver, D. (1982): Multiattribute Evaluation. SAGE Publications, Newbury Park, California.

[11] Gowda, M. J. C., Jayaramaiah, K. M. (1998): Comparative evaluation of rice production systems for their sustainability. - Agric Ecosystem Environ 69(1): 1-9.

[12] Garg, N. K., Dadhich, S. M. (2014): Integrated non-linear model for optimal cropping pattern and irrigation scheduling under deficit irrigation. - Agric. Water Manage. 140: 1-13.

[13] Garg, R. K., Agrawal, V. P., Gupta, V. K. (2007): Coding, evaluation and selection of thermal power plants-A MADM approach. - Int. J. Electric. Power Energy Syst 29(9): $657-668$.

[14] Geng, G., Wardlaw, R. (2013): Application of multi-criterion decision making analysis to integrated water resources management. - Water Resource Manage. 27(8): 3191-3207.

[15] Ishikawa, A., Amagasa, M., Shiga, T., Tomizawa, G., Tatsuta, R., Mieno, H. (1993): The max-min Delphi method and fuzzy Delphi method via fuzzy integration. - Fuzzy Sets and Systems 55: 241-253.

[16] Li, Z., Wong, W. K., Kwong, C. K. (2013): An Integrated Model of Material Supplier Selection and Order Allocation Using Fuzzy Extended AHP and Multiobjective Programming. - Mathematical Problems in Engineering 2013, ArticleID363718: 14.

[17] LINGO (2006): Linear, Integer, Nonlinear and Global Optimization Package, Release 10.0. - Lingo System Inc., Chicago, USA, http://www.lindo.com

[18] Klir, G. J., Yuan, B. (1995): Fuzzy sets and fuzzy logic - Theory and application. - New Jersey: Prentice-Hall Inc.

[19] Qureshi, M. N., Singh, R. K., Hasan, M. A. (2017): Decision support model to select crop pattern for sustainable agricultural practices using fuzzy MCDM. - Environmental Development and Sustainability, International Journal Springer 1-19, USA, DOI 10.1007/s10668-016-9903-7

[20] Ministry of Agriculture and Water (2001a): Agriculture Statistical Year Book 13. - Saudi Arabia.

[21] Ministry of Agriculture and Water (2001b): Indicators for Agriculture and Water. - Saudi Arabia.

[22] Mutikanga, H. E., Sharma, S. K., Vairavamoorthy, K. (2011): Multi-criteria decision analysis: a strategic planning tool for water loss management. - Water Resource Manage 25(14): 3947.

[23] Nambiar, K. K. M., Gupta, A.P., Fu, Q., Li, S. (2001): Biophysical, chemical and socioeconomic indicators for assessing agricultural sustainability in the Chinese coastal zone Agric Ecosystems Environ 87(2): 209-214.

[24] Noorderhaben, N. (1995): Strategic decision making. - UK: Addison-Wesley.

[25] Peacock, C., Sherman, D. M. (2010): Small ruminant research, sustainable goat production - Some global perspectives. - Small Ruminant Research 89(2-3):70-80 
[26] Pramanik, M. K. (2016): Site suitability analysis for agricultural land use of Darjeeling district using AHP and GIS techniques. - Modeling Earth Systems and Environment 2:56. doi: 10.1007/s40808-016-0116-8.

[27] Qureshi, M. R., Singh, R. K., Hasan, M. A. (2018): Decision support model to select crop pattern for sustainable agricultural practices using fuzzy MCDM. - Environ Dev Sustain 20: 641-659

[28] Raju, K. S., Vasan, A. (2007): Multi attribute utility theory for irrigation system evaluation. - Water Resource Manage. 21(4): 717-728.

[29] Raju, K. S., Duckstein, L., Arondel, C. (2000): Multicriterion analysis for sustainable water resources planning: a case study in Spain. - Water Resource Manage 14(6): 435-456.

[30] Rao, P. V., Baral, S. S. (2011): Attribute based specification, comparison and selection of feed stock for anaerobic digestion using MADM approach. - J. Hazard. Mater. 186(2): 2009-2016.

[31] Rao, R. V., Patel, B. K. (2010): A subjective and objective integrated multiple attribute decision making method for material selection. - Mater. Des. 31: 4738-4747.

[32] Roy, R., Chan, N. W. (2012): An assessment of agricultural sustainability indicators in Bangladesh: review and synthesis. - Environmentalist 32(1): 99-110.

[33] Roozbahani, A., Zahraie, B., Tabesh, M. (2012): PROMETHEE with precedence order in the criteria (PPOC) as a new group decision making aid: an application in urban water supply management. - Water Resource Manage 26(12): 3581-3599.

[34] Saaty, T. L. (1980): Analytic hierarchy process. - John Wiley \& Sons, Ltd.

[35] Shrivastava, S. K., Verma, M. K., Devatha, C. P. (2012): Optimization modelling for crop planning of hasdeo bango command. - Int. J. Eng. Res. Technol. 1(9): 1-13.

[36] Song, J. Y., Chung, E. S. (2016): Robustness, uncertainty and sensitivity analyses of the TOPSIS method for quantitative climate change vulnerability: A case study of flood damage. - Water Resource Manage 30(13): 4751-4771.

[37] Srdjevic, B., Medeiros, Y. D. P., Faria, A. S. (2004): An objective multi-criteria evaluation of water management scenarios. - Water Resource Manage 18(1): 35-54.

[38] Sorensen, A. A., van Beest, F. M., Brook, R. K. (2015): Quantifying overlap in crop selection patterns among three sympatric ungulates in an agricultural landscape. - Basic and Applied Ecology 16(7): 601-609.

[39] Srinivas, R., Singh, A. P., Sharma, R. (2017): A scenario based impact assessment of trace metals on ecosystem of river ganges using multivariate analysis coupled with fuzzy decision-making approach. - Water Resource Manage: 1-21 Tran, L.D.

[40] Sydorovych, O., Wossink, A. (2008): The meaning of agricultural sustainability: evidence from a conjoint choice survey. - Agric Syst 98(1): 10-20.

[41] Venkata Rao, R. (2008). Evaluating Flexible Manufacturing Systems Using a Combined Multiple Attribute Decision Making Method. - International Journal of Production Research 46(7): 1975-1989.

[42] Zhen. L., Routray, J. K., Zoebisch, M. A., Chen, G., Xie, G., Cheng. S. (2005): Three dimensions of sustainability of farming practices in the North China Plain: a case study from Ningjin County of Shandong Province, PR China. - Agricultural Ecosystem Environ 105(3): 507-522.

[43] Zhen, L., Zoebisch M. A., Chen, G., Feng, Z. (2006): Sustainability of farmers' soil fertility management practices: a case study in the North China Plain. - J Environ Manage 79(4): 409-419. 